\title{
EDUCAÇÃO AM BIENTAL: QUE CRITÉRIOS ADOTAR PARA AVALIAR A ADEQUAÇÃO PEDAGÓGICA DE SEUS PROJETOS?
}

\author{
M aria Guiomar Carneiro Tomazello* \\ Tereza Raquel das Chagas Ferreira**
}

\begin{abstract}
Resumo: M uitos autores reconhecem as dificuldades de avaliar e analisar as repercussões de atividades de educação ambiental devido aos vários processos educativos existentes, à abrangência dos temas e dos objetivos. Se utilizarmos processos de avaliação mais quantitativos, que requerem respostas objetivas, podemos prescindir de elementos que melhor caracterizam a Educação Ambiental. Necessitamos, portanto, de instrumentos adequados de avaliação. N este trabal ho pretendemos destacar os processos educativos em Educação Ambiental e as discussões sobre critérios de avaliação de projetos na visão de vários especialistas
\end{abstract}

\section{Unitermos: Educação Ambiental; Avaliação; Ensino de Ciências}

Abstract: $M$ any authors recognize the difficulties in evaluating and analysing the repercussions of the activities in Environmental Education, due to the various existing assesment processes, the comprehending character of the themes and objectives. If we use more quantitative assessment processes, requiring objetive responses, we may abdicate of elements that best characterize the Environmental Education. Therefore, we need adequate evaluation instruments. In this paper, we intend to point out the educational processes in Environmental Education, and the discussions about the assesment criteria for projects according to various specialistś views

Keywords. Environmental Education, Evaluation, Science Teaching

\section{Introdução}

N esta última década, a educação ambiental tem experimentado no Brasil um grande crescimento. Recentemente, a área de M eio Ambiente foi incluída como um dos temas transversais nos Parâmetros Curriculares N acionais-PCN s, centrando-se o trabalho pedagógico "no desenvolvimento de atitudes e posturas éticas e, no domínio de procedimentos, mais do que na aprendizagem de conceitos (PCNs, 1998, p.201). Ainda que de forma incipiente, muitos professores têm dedicado parte de seu trabalho em sala de aula às questões ambientais, isso sem contar as inúmeras iniciativas nesta área tomadas por organizações não-governamentais, centros comunitários, empresas, mídia, dentre outros.

Como avaliar a adequação desses projetos? Muitos autores reconhecem as dificuldades em avaliar e analisar as repercussões de atividades de educação ambiental devido à abrangência dos temas e dos objetivos, pois educar ambientalmente é educar a partir da concepção de uma realidade complexa, isto é, em que todos os elementos constituintes do ambiente estão em contínua interação. Como avaliar em que medida os alunos vão incorporando e consolidando determinados valores, atitudes e hábitos ao longo de

\footnotetext{
* Professora Doutora, Grupo de Área de Física, Faculdade de Ciências Matemáticas e da Natureza, Programa de PósGraduação em Educação, Universidade Metodista de Piracicaba, UNIMEP, Piracicaba, SP, Brasil (e-mail:mgtomaze@unimep.br)

** M estre em Educação, U niversidade M etodista de Piracicaba, U N I M EP, Piracicaba, SP, Brasil
} 
sua escolaridade? A avaliação de um projeto de educação ambiental torna-se particularmente difícil, pois os resultados não têm uma relação direta com uma atividade ou com um estudo sobre um tema.

Segundo Tarin (1994), se adotarmos processos de avaliação mais rígidos e quantitativos, correremos 0 risco de prescindir de elementos que melhor caracterizam a educação ambiental. A avaliação utilizada na escola tradicional não se adequa a esta nova visão de realidade ambiental, portanto necessitamos não só de novas práticas educativas como de um novo modelo de avaliação.

N este trabalho pretendemos focalizar as discussões sobre avaliação de projetos de educação ambiental na visão de vários especialistas.

\section{A evolução dos valores em relação ao M eio ambiente ${ }^{1}$}

Se atentarmos para a evolução dos princípios de proteção ambiental, ocorrida ao longo do século XX, deparamo-nos com mudanças significativas que vão da estética à ética. 0 quadro 1, a seguir, mostra a evolução desses valores.

\section{Q uadro 1- Evolução dos princípios de proteção ambiental no século XX}

\begin{tabular}{|l|l|l|l|}
\hline D ata & Valor social & M eio ambiente & Princípio \\
\hline 1900 & Progresso/Tecnologia & Parques e santuários & Estético \\
\hline 1960 & Q ualidade de vida/C onsumo & Tratamento da contaminação & Bem estar \\
\hline 2000 & Preservação & D esenvolvimento sustentável & Ética \\
\hline
\end{tabular}

Fonte: Calvo e Corraliza (1994), citados por D íaz (1995, p. 27)

No final do século XIX e início do século XX, tendo como princípio a conservação da natureza, muitos países, inclusive o Brasil, passaram a proteger amostras do ambiente natural por meio de Parques $\mathrm{N}$ acionais. 0 objetivo principal dessas áreas protegidas residia na preservação de paisagens naturais, segundo seu val or estético e de acordo com a possibilidade de uso da geração atual e das futuras, não permitindo a presença do ser humano.

$\mathrm{N}$ as décadas de 40 e 50 , os ambientalistas produziram obras importantes sob o enfoque da ruptura do equilíbrio natural causada por entes abstratos, o "homem" e a "civilização", sendo que, na década de 60, um grupo de cientistas, reunidos no chamado Clube de Roma, fez um alerta para os riscos de um crescimento contínuo baseado em recursos naturais esgotáveis. 0 relatório "Limites do Crescimento", publicado em 1972, teve o mérito de conscientizar a sociedade sobre os limites da exploração do planeta.

Após a Conferência de Estocolmo sobre Meio Ambiente, em 1972, as nações começaram a estruturar seus órgãos ambientais e estabelecer suas legislações, visando 0 controle da poluição ambiental e, na década de 80 , os resíduos perigosos passaram a ocupar lugar de destaque nas discussões sobre contaminação ambiental com o propósito de se garantir a qualidade de vida, o bem estar da humanidade.

$\mathrm{N}$ a década de 90 , a Conferência das $\mathrm{N}$ ações Unidas sobre M eio Ambiente e 0 D esenvolvimento, conhecida como Cúpula da Terra ou Rio 92, mostrou que neste final de século a questão ambiental ultrapassa os limites das ações isoladas e localizadas, para se 
constituir em uma preocupação de toda a humanidade. A Agenda 21, documento elaborado na Rio 92, configura-se como uma estratégia de sobrevivência para o século XXI. Ela estabe lece compromissos e intenções para a preservação e melhoria da qualidade ambiental, visando a sustentabilidade da vida na Terra. $\mathrm{N}$ os seus 40 capítulos, trata das dimensões econômicas e sociais; da conservação e manejo de recursos naturais; do fortalecimento da comunidade; e de meios de implementação. N ovas contribuições tendem a reforçar, ao menos no âmbito teórico, a articulação entre as questões ambientais e o processo de desenvolvimento a partir de princípios éticos.

Também na escola, a educação ambiental tem se modificado profundamente e há, cada vez mais, uma consciência que mudanças substanciais devam acorrer em busca de uma nova ética que permeie os nossos comportamentos e a nossa relação com o ambiente.

Segundo Mayer (1998), nos anos 50-60 o meio ambiente era utilizado como expediente pedagógico que possibilitava 0 envolvimento ativo dos alunos. Já nos anos 70, com o reconhecimento da importância da ecologia, a educação ambiental passou a ser ensinada junto com as outras ciências naturais. Mais tarde, no final dos anos 70, com 0 descobrimento dos riscos ambientais, com os desastres ecológicos, noções sobre a importância dos recursos naturais e os prejuízos causados pela poluição foram introduzidas nos livros didáticos.

N este início de novo século, a educação ambiental deve ser capaz de gerar propostas adequadas, baseadas em valores e condutas sociais ambientalmente favoráveis para um mundo em rápida evolução.

\section{Os processos educativos em Educação Ambiental}

O s processos educativos mais adequados em Educação Ambiental, de acordo com os objetivos que se desejam alcançar, foram propostos por Lucas (1980-81), edistinguem educação sobre, no e para 0 ambiente. Apesar de termos claro que muitas combinações entre esses três componentes ocorrem simultaneamente, vamos, a seguir, destacar cada um deles.

Educação sobre ou acerca do ambiente compreende ações ou atividades educativas que têm como objetivo proporcionar informações e formação sobre o meio ambiente e relações que se dão nele. As intenções educativas são, fundamentalmente, de natureza cognitiva, visam o conhecimento de vários aspectos do ambiente. Seus objetivos incluem a compreensão cognitiva das interações entre os seres humanos e seu meio. As ações dirigidas para 0 ambiente e seus problemas apóiam-se basicamente no conhecimento. Como exemplo de atividade sobre 0 ambiente teríamos a análise da influência das atividades domésticas e industriais de uma cidade sobre a qualidade da água da região, estudo das relações entre vegetação e solo, adubação, plantio de mudas, efeitos do aterro sanitário em águas subterrâneas, dentre outros (Jiménez Aleixandre, 1995; M áximo-Esteves, 1998).

Para Mayer (1998), a premissa desse primeiro processo educativo é que os problemas ambientais são causados por uma fal ta de "conhecimentos" e que a solução reside, portanto, na "informação". Se conhecêssemos os problemas não nos comportaríamos de forma inadequada. Se isso fosse verdadeiro, conclui a autora, como explicaríamos que justamente nos países mais desenvolvidos em Ciência e Tecnologia e em termos de seus sistemas educativos ocorrem os maiores problemas ambientais?

Educação no ou através do ambiente toma o meio físico como recurso didático duplo: como meio para investigar e descobrir o mundo por meio da observação e do 
contato direto e, também, como ponto de partida para desenvolver projetos de aprendizagens integradas. 0 recurso às situações da vida real, que acontecem fora da sala de aula, em ambientes próximos ou não aos alunos envolve, por exemplo, estudo de campo para conhecer os diferentes tipos de solo e de rochas, análise da erosão do solo, estudo das espécies de árvores do parque da escola, trilhas ecológicas para observação de plantas e animais, visitas a zoológicos e a jardins botânicos, planetários, dentre outros (Jiménez Aleixandre 1995, M áximo-Esteves, 1998).

A educação no ambiente reconhece que os comportamentos vêm guiados muito mais pelas nossas emoções e valores do que por nossos conhecimentos, portanto é necessário não só oferecer aos educandos informações como propor experiências que reconstruam a conexão entre 0 homem e a natureza. N esse caso, a teoria implícita é que 0 vínculo emotivo com o meio ambiente será suficientemente forte para promover mudanças de comportamento. Com freqüência, a educação no ou através do ambiente invoca a proteção e a conservação de uma natureza que, seguramente, sobreviverá à nossa espécie. As proposições conservacionistas fundamentadas na reprodução de ecossistemas naturais em equilíbrio permanente, tais como parques e áreas de proteção ambiental não consideram, entretanto, que é impossível anular a ação humana sobre eles, mas apenas regulá-la. $N$ ão podemos continuar a considerar a degradação hoje existente como decorrente de ações de entes abstratos. Se não quisermos que a ação do homem continue a ser depredadora, devemos substituir por novas as velhas relações capitalistas e introduzir um novo sistema produtivo, repensando as formas de mediação entre seres humanos e o meio natural, sem desconsiderar as contribuições da Ciência e da Tecnologia (Bressan, 1996; M ayer, 1998).

Em outras palavras, procura-se hoje a construção de um modelo de gestão ambiental que seja capaz de apreender o valor intrínseco do patrimônio natural sem esquecer, no entanto, o seu interesse para o progresso da humanidade. D e acordo com O rlandi (1996), não se trata de "proteger" a natureza, mas sim, o homem. Trata-se de não evitar a necessidade da transformação da natureza pelo homem. A educação para 0 ambiente é a parte mais relevante e inovadora do processo, pois tem como objetivo a conservação e a melhoria do meio, isto é, pretende-se, além da aquisição de conhecimentos e de capacidades, desenvolver no indivíduo o envolvimento emocional e o compromisso na procura de soluções para os problemas ambientais. 0 meio ambiente é, portanto, o ambiente que nos cerca, cotidiano, aquele em que pequenas iniciativas podem começar a modificar atitudes e modos de atuar. A educação para o ambiente traduz no campo educativo o lema "atuar localmente e pensar globalmente". 0 objetivo final da educação para o ambiente é conseguir mudanças de atitudes que não serão efetivas se não vierem acompanhadas de mudanças de hábitos/comportamentos. Educação para 0 ambiente deveria incluir como objetivo, ao se estudar a contaminação de um rio, por exemplo, a tomada de decisões e opções para diminuir essa contaminação tanto no âmbito pessoal - o que posso e devo fazer enquanto cidadão - como desde o coletivo - estar atento a acompanhar as decisões das instituições responsáveis (Jiménez Aleixandre, 1995; M áximo-Esteves, 1998).

Para M ayer (1998), durante os últimos 25 anos, o caráter da educação ambiental modificou-se profundamente não só porque os trêês processos educativos propostos por Lucas sobre, no e para o ambiente - têm sido pouco a pouco substituídos uns pelos outros, mas porque este é um processo que tem exigido reflexões para se chegar ao nível das atuais propostas de muitas escolas e de muitas associações ecológicas que aceitam e propõem um triplo enfoque para a Educação Ambiental, ou, como poderíamos chamar, de enfoque complexo da Educação Ambiental. 
Um processo educativo com um triplo enfoque em Educação Ambiental passa tanto pelos valores, emoções, conhecimentos, interpretações e compreensões dos fenômenos ambientais como pelas mudanças de atitudes e de hábitos/comportamentos. A preocupação com o estabelecimento de novos hábitos já fazia parte dos objetivos da Educação Ambiental, estabe lecidos na I C onferência Intergovernamental sobre Educação Ambiental ocorrida em T bilisi, na G eorgia, em 1977, e reiterados em outros encontros: a Educação Ambiental tem por objetivo etabelecer novas normas de conduta em indivíduos e grupos e na sociedade em geral, em relação ao meio ambiente (Fensham et al, 1996).

Cabe aqui ressaltar que os termos atitude, hábito e/ou comportamento não têm 0 mesmo significado. Atitudes favoráveis sobre o meio ambiente nem sempre implicam comportamentos e hábitos responsáveis. Atitude é entendida como tendência a querer atuar de uma forma determinada diante de um tipo de situação, enquanto que comportamento é entendido como atuação concreta. O s comportamentos são expressos por hábitos e costumes que muitas vezes dificultam ações mais positivas frente a diversos problemas ambientais.

Para Silva (1996), o comportamento corresponde às reações de um indivíduo num determinado tempo e lugar, enquanto que atitude representa o modo de ser em uma situação, e depende de fatores individuais e sociais, representando uma predisposição valorativa da pessoa, da qual resulta a sua maneira de agir. Podemos identificar nas atitudes três componentes básicos: um cognitivo (forma como o objeto da atitude é percebido), um afetivo (sentimento de inclinação ou de aversão da pessoa em relação ao objeto da atitude) e um comportamental (tendência comportamental em relação ao objeto da atitude). Portanto, a própria noção de comportamento já está embutida na de atitude, tornando difícil uma distinção rígida.

M udanças de comportamento são mais facilmente reconhecidas porque são mais evidentes e observáveis (Patterson e Eisemberg, 1988 apud Silva, 1996). Por outro lado, mudanças de atitudes não podem ser avaliadas diretamente, embora possam ser detectadas pela conduta ou pela produção verbal do indivíduo. Por essa razão, Bernardo (1982), apud Silva (1996), as denomina mudanças de constructos. Tais constructos representam uma visão particular da realidade, já que as pessoas se comportam com base no que acreditam ser verdade, não com base na realidade objetiva.

O s processos educativos em Educação Ambiental aqui expostos, sejam na educação formal quanto na informal, nos dão a dimensão das dificuldades em avaliar as repercussões de um projeto de Educação Ambiental, pois, parafraseando Sanmartí (1994), os resultados de um processo educativo não são conseqüência de uma só atividade, mas de uma ação prolongada por anos, além de que, o tempo dedicado ao ensino não coincide necessariamente com o tempo de aprendizagem. Algo que se ensina em uma determinada época e em um determinado contexto pode influenciar o comportamento de uma pessoa em um outro e inesperado momento.

\section{Critérios para avaliação de um projeto de Educação Ambiental}

De todas as tarefas de um educador, talvez a avaliação seja a mais difícil. Reconhecemos as limitações e a complexidade do processo de avaliação, principalmente em se tratando de educação ambiental, pois, como objetivamos a mudança de atitudes e hábitos/comportamentos, como conhecer as repercussões causadas por uma atividade e/ou projeto de Educação Ambiental? C omo avaliar se precisamos mel horar/retomar as atividades 
propostas? Como decidir que tipo de instrumentos e/ ou situações podem ser mais adequados para obtermos informações relevantes sobre a pertinência de uma atividade? Todas essas questões e outras mais, certamente, surgem ao longo do processo do desenvolvimento das atividades de Educação Ambiental.

H á uma unanimidade entre os autores sobre o papel fundamental da avaliação dos projetos e/ou atividades de Educação Ambiental e sobre a importância do desenvolvimento de instrumentos adequados de avaliação. Vejamos como se posicionam os especialistas quanto à esta questão.

Guimarães (1995) acredita ser importante realizar uma avaliação no decorrer de todo o desenvolvimento de atividades de Educação Ambiental. Propõe uma avaliação qualitativa da produção de conhecimentos para que se possa acompanhar o processo.

Alba e Gaudiano (1997, p.13) também consideram que a avaliação precisa ser um processo contínuo e ocorrer em todas as fases do desenvolvimento das atividades: Está associada com todo o processo educativo. $\mathrm{N}$ ão a concebemos só como uma atividade final, nem diagnóstica, senão como um processo estreitamente articulado com o fazer educativo.

Os autores apontam possibilidades de se desenvolver Educação Ambiental na escola, se:

- Os problemas ambientais, suas origens e formas de intervenção em sua solução ou prevenção, se encontram articulados com os conteúdos e práticas escolares cotidianas,

-no reconhecimento desses problemas haja a participação dos alunos, a partir de seus pontos de vista e val orações;

- na decisão sobre as medidas a adotar para participar, os alunos, assim como os pais, tenham a oportunidade de expressar suas próprias prioridades e elas sejam levadas em conta;

-na avaliação dos avanços e os alcances das ações se outorgue valor aos eforços realizados, mais no sentido de entendêlos como parte de um processo de grande visão do que em função de conseguir metas de curto prazo (p. 25-26).

Guerra (1993) propõe a avaliação como um processo de diálogo, compreensão e melhoria de programas educativos, já que ela interroga pelo seu valor educativo, sua importância, exigências e significados; e se etabelece como um meio de entendêlos e melhorá-los. Para o autor, a avaliação deve ser independente, não neutra; 0 avaliador deve ser imparcial, mas não asséptico. A avaliação deve ser qualitativa e tem por objetivo melhorar os programas através de sua compreensão, do conhecimento de sua natureza e resultados. Ela deve ser democrática, deve ser posta a serviço dos usuários e da comunidade. D eve ser processual, isto é, realizar-se durante todo o processo, assim pode modificar e melhorar. É essencial que seja participativa, dê voz aos participantes para que emitam suas opiniões. D eve realizar-se em equipe, pois assim haverá uma pluralidade de enfoques e maior garantia de rigor. Pode ser feita pelos próprios participantes etambém contar com a colaboração externa, com uma perspectiva complementar, o que dará maior veracidade às informações. Vale ressaltar que o processo de avaliação não objetiva o julgamento do programa ou dos seus responsáveis. Sua função é facilitar através das informações recolhidas, de sua interpretação, a valoração, que deve ser feita pelos próprios participantes; eles sim devem emitir juízos para o aperfeiçoamento tanto do programa como dos profissionais envolvidos. 
A avaliação permitirá a compreensão e a reflexão, por meio dessas informações selecionadas, ampliando assim a produção de conhecimentos sobre o programa.

Concordamos com Pedrini (1997, p.100), quando afirma:

A constatação da ausência de qualquer tipo de avaliação é demais preocupante, pois desconhecendo a eficácia ou eficiência de nossas ações a curto, médio ou longo prazos não podemos proceder a eventuais correções ou ajustes do nosso processo de construção e difusão do conhecimento gerado e da aquisição de novos hábitos por parte dos capacitandos.

M ayer (1989) considera que para avaliar qualquer projeto de Educação Ambiental há de se ter três grupos de indicadores de qualidade. 0 primeiro, considerado por ela como o mais importante, centra-se na mudança de valores, atitudes, hábitos e crenças dos alunos. 0 segundo grupo de indicadores descreve a estratégia educacional do projeto sob o ponto de vista cognitivo (relevância local do projeto, enfoque multi/inter/transdisciplinar) enquanto que o terceiro descreve a estratégia educacional do projeto do ponto de vista afetivo, isto é, descreve as interações entre alunos, professores, família, comunidade e autoridades

Sanmartí (1994), apoiada nos indicadores definidos por M ayer (1989), considera que as seguintes questões poderiam ser formuladas, na análise da adequação de um projeto de educação ambiental:

1-0 tema selecionado é relevante em relação ao meio ambiente do aluno?

2-0 projeto prevê a promoção de ações dos indivíduos em favor do meio?

3-Permite estabelecer relações entre os problemas locais e os problemas globais do planeta?

4-Supera os limites da sala de aula, isto é, tem conseqüências no âmbito familiar e em relação à comunidade?

5-0 bservam-se mudanças de atitudes dos alunos em relação ao meio ambiente?

6-0 bservam-se mudanças de hábitos/comportamentos?

7-Observam-se mudanças dos modelos explicativos sobre os problemas ambientais? Aumentou o seu grau de complexidade?

8-M elhorou a capacidade de análise e de tomada de decisões por parte dos alunos?

Em um encontro sobre Educação Ambiental, ocorrido em Toulouse/França, em setembro de 1994, segundo Diaz (1995), foram estabelecidas algumas estratégias pedagógicas para a avaliação de um projeto de Educação Ambiental. D evem ser avaliados 0 desenvolvimento do espírito crítico do aluno, o desenvolvimento de capacidades, tais como responsabilidades, iniciativa e autonomia, e o desenvolvimento de uma nova ética e valores, melhor adaptados à gestão dos recursos e a responsabilidade ante às gerações futuras (valores de solidariedade, tolerância, cooperação).

Para Diaz (1995), são três os níveis de avaliação em Educação Ambiental: alunos, professores e projeto educativo. Q uanto aos alunos, devem se levadas em conta as mudanças de atitude e de manifestações da capacidade de analisar os problemas, tomar decisões e intervir no meio ambiente. Segundo o autor, a educação ambiental deve incidir favoravelmente nas 
relações docente- discente; portanto, isso também deve merecer atenção. D o ponto de vista dos professores, algumas competências novas devem ser reconhecidas e avaliadas, tais como a capacidade de elaborar, concluir e participar de um projeto interdisciplinar e/ou transdisciplinar; capacidade de integrar os objetivos da Educação Ambiental nas diferentes disciplinas e determinar um marco conceitual comum; capacidade de apreciar eresponder às necessidades da comunidade local com a perspectiva de um desenvolvimento sustentável, e a capacidade de introduzir uma dimensão mais global da Educação Ambiental. Q uanto ao projeto, devem ser avaliados cada um dos elementos que o compõem: os objetivos, recursos previstos, formas de relação entre os próprios alunos e entre alunos e professores, metodologia e o próprio sistema de avaliação.

De acordo com Glasgow et al (1995), a principal dificuldade da planificação da avaliação em Educação Ambiental está em definir os seus objetivos. O s objetivos a se alcançar devem ser precisos e claros. Por exemplo, a Educação Ambiental aspira, dentre outros objetivos mais gerais, a ajudar os indivíduos a tomar consciência do entorno global, ou seja, compreender que 0 entorno global abrange o conjunto de aspectos culturais, sociais e culturais; compreender que esses aspectos são interdependentes e estão em constante interação, e dar-se conta de que eles mesmos são parte integrante desse entorno. Se, dentro desse assunto se elegem os aspectos sociais do meio escolar, o projeto poderia ter como objetivos espeć́ficos capacitar os alunos a: i) identificar os diferentes grupos sociais dentro do meio escolar; ii) exemplificar interações que esses grupos mantêm e iii) avaliar o impacto sobre o meio escolar em seu conjunto, de um tipo concreto de interações entre os distintos grupos.

A pesar de algumas proposições diferenciadas, observa-se nos posicionamentos dos vários autores uma premissa comum, que é a mudança de valores. No nosso entender, se são valores que desejamos mudar, devemos planejar, no momento da elaboração de um projeto de Educação Ambiental, atividades com características próprias, específicas, que as mudanças de atitudes e comportamentos exigem. Entretanto, não são quaisquer valores, ou os valores pré-estabelecidos pela sociedade. A escola deve avançar em suas propostas na busca de valores que melhor se adaptem na luta pela sobrevivência da espécie humana e melhorem a gestão dos recursos naturais.

Finalizando, acreditamos ser importante não só avaliar como também superar a visão simplista de avaliação. N ão se avalia com 0 único objetivo de propor mudanças, pois nem sempre mudança significa melhoria. $0 \mathrm{~s}$ resultados da avaliação de um projeto de Educação Ambiental devem sinalizar, por meio da compreensão, da reflexão e do diálogo entre seus atores - professores, alunos e comunidade - os elementos que consistiriam na autêntica melhoria do programa.

\section{Referências bibliográficas}

ALBA, A., GAU DIAN O, E.G. Evaluación de programas de Educación Ambiental. M éxico: Universidade $N$ acional Autônoma do M éxico,1997.

BRASIL. Secretaria de Educação Fundamental. Parâmetros curriculares nacionais: ciências naturais. Brasília: M EC/SEF, 1997.

BRESSAN , D. Gestão racional da natureza. São Paulo: Hucitec, 1996.

DIAZ, A. P. La educación ambiental como proyecto. Cuadernos de Educación, Barcelona,

I.C.E. Universitat Barcelona- Editorial H orsori, n. 18, 1995. 
FEN SH AM P.; H UN W ICH , J.; JACO BSO N . Programa de formación en educación ambiental para futuros professores y asesores de ciencias de enseñanza secundaria. In: UN ESC O -PN U M A. Programa Internacional de Educación Ambiental. Bilbao: Los libros de Catarata, 1996. (Serie de Educación Ambiental, 7)

GLASG OW, J.; RO BIN SO N, P.; JACOBSO N, W. Programa de introducción a la educación ambiental para maestros e inspectores de enseñanza primaria. In: U N ESCO PN U M A. Programa Internacional de Educación Ambiental. Bilbao: Los libros de Catarata, 1995. (Serie de Educación Ambiental, 5)

GUERRA, M .A.S. La evaluación: un proceso de diálogo, comprensión y mejora. Investigácion en la escuela, n. 20,1993.

GUIM ARÃES, M .A. A dimensão ambiental na educação. Campinas: Papirus, 1995.

JIM ÉN EZ ALEIXAN D RE, M .P. Integrando la educación ambiental en el currículum de ciencias. Alambique: Didática de las ciencias experimentales, v. 2, n. 6, oct. 1995.

LU CAS, A.M . The role of science education in education for the environment. Journal of Environmental Education, v. 12, n. 2, p. 32-37, 1980/81.

M AXIM O - ESTEVES, L. D a teoria à prática: educação ambiental com as crianças pequenas ou o fio da história. Porto: Porto Editora, 1998.

M AYER, M. Evaluation the outcomes of environment and schools initiatives. CEDE- Centro Europeo D ell Educazione, 1989.

. Educación Ambiental: de la acción a la investigación. Enseñanza de las

Ciencias, v. 16, n. 2, jun.1998.

O RLAN D I, E.P. Enfoque linguístico discursivo: 0 discurso da educação ambiental. In: TRAJBER, R. \& M AN ZO CHI, L.H . (O rgs.) Avaliando a educação ambiental no Brasil: materiais impressos. São Paulo: Gaia, 1996.

PED RIN I, A.G .(O rg.). Educação Ambiental: reflexões e práticas contemporâneas. Petrópolis: Vozes, 1997.

SAN M ART Í, N . L'educació ambiental a l'escola: reflexions des de l' àrea de Ciències Experimentais/ L'educació ambiental a l'escola: noves línies de reflexió i actuació. D ossiers Rosa Sensat, 1994.

SILVA, M .L.R. M udanças de comportamentos e atitudes. São Paulo: M oraes, 1996.

TARIN , R. Cal avaluar els projectes d'educació ambiental que fem a l'escola? L'educació ambiental a l'escola: noves línies de reflexió i actuació. D ossiers Rosa Sensat, 1994.

TO M AZELLO , M .G.C. Evolução dos princípios de proteção ambiental: da estética à ética. Comunicações: Caderno do Programa de Pós-Graduação em Educação, Piracicaba, Universidade M etodista de Piracicaba, v. 6, n. 2, nov. 1999.

\section{Artigo Recebido em: 17/04/00 \\ Artigo Aceito para Publicação em: 03/08/01}


